\title{
EVIDENCE THAT BODY IRRITATIONS OR EMOTIONS RETARD GASTRIC EVACUATION, NOT BY PRODUCING PYLORO- SPASM BUT BY DEPRESSING GASTRIC MOTILITY ${ }^{1}$
}

\author{
By J. P. QUIGLEY, H. J. BAVOR, M. R. READ, AND B. L. BROFMAN \\ (From the Department of Physiology, Western Reserve University Medical School, Cleveland)
}

(Received for publication April 20, 1943)

The impression is prevalent that pylorospasm results from emotions or through viscero-visceral or somato-visceral reflexes, initiated by irritation of any portion of the body. It is also believed that the delay in gastric evacuation which results from such irritation is largely or entirely due to this pylorospasm. Much of the evidence on which these concepts rest may be questioned, since it consists of rather indirect observations or of studies, by more direct methods, performed on anesthetized. animals. Representative of the first group are the studies of Cole (1) who concluded that lesions near the sphincter produced pylorospasm, since on $x$-ray examinations in which gastric evacuation could not be detected, he observed barium lying in longitudinal striations in the sphincter. In the second group, Carlson and Litt (2) observed, in anesthetized dogs having a balloon which was rapidly inflated and deflated in the sphincter, that stimulation of many visceral sensory and at least some somatic sensory nerves induced a temporary contraction or spasm of the pylorus.

The original investigators or the subsequent commentators have usually assumed that any delay in gastric evacuation resulted from pylorospasm. On such a premise, supposed evidence has accumulated that pylorospasm results from irritation or distention of the duodenum ( 3 to 5 ), the appendix $(4,6$ to 8$)$, the colon (8 to 13) and the gall bladder $(4,6,8)$. Hughson (14) presented evidence that irritation of any of the viscera in or near the abdominal cavity produced pylorospasm through an influence on the peritoneum. In these studies, the reports of experimental and clinical investigations mutually supported each other.

Barber and Stewart (4) and Smith and Miller (8) have reported a marked increase in gastric tone and motility from irritation of the colon, ap-

1 This investigation was aided by a grant from the Council on Pharmacy and Chemistry of the American Medical Association. pendix, or gall bladder, but practically all other investigators $(12,15$ to 19$)$ obtained an inhibition of the empty or digesting stomach from body irritations. According to the older concept, gastric inhibition should be associated with pylorospasm, for it was believed that these structures acted in opposition to each other. However, the fact that gastric inhibition would in itself adequately explain the delayed gastric evacuation produced by noxious bodily stimuli was largely ignored. Now it appears to be well-established $(a)$ that the stomach and sphincter under most circumstances behave, not in a contrary but in a similar manner, i.e., react as a unit $(20,21)$, and $(b)$ that gastric evacuation is controlled more by gastric peristalsis than by pyloric closure $(22,23)$. Also, several improved methods of studying pyloric sphincter activity have been recently developed. It therefore appeared advisable to reinvestigate the development and importance of pylorospasm in the delay of gastric evacuation produced by noxious bodily stimuli.

In the present investigation on unanesthetized dogs, we have irritated various parts of the body and have attempted to determine the effects not only on the pyloric sphincter but simultaneously, on the motility of the pyloric antrum and duodenal bulb and on the gastric evacuation process. We have employed several methods which are more direct than those ordinarily employed, but we have also included roentgenological studies.

A series of 9 dogs were provided, by the method of Meschan and Quigley (21), with permanent cannulae giving access to the gastric and duodenal luminae. These animals were trained to lie in comfortable hammocks and to cooperate with the experimental procedures.

Triple balloon technic. Three balloons in tandem fashion were arranged, by the method of Meschan and Quigley, to record by water manometers the motor activity of the pyloric antrum, sphincter, and duodenal bulb in fast- 
ing animals. This method does not accurately register the pressures in the 3 portions of the gut, but it certainly indicates whether these regions are in spasm or are relaxed, and it gives an approximation of the degree of tonus and motility intermediary between these extremes.

Nervous states. It is well-known that mental reactions (worry, nervousness, etc.) can influence gastro-intestinal motility and many clinicians (6, 24) believe that such reactions frequently produce pylorospasm. We have made a large number of determinations of the effect of nervous reactions on pyloric region activity, both intentionally in this investigation and incidentally in several similar studies. These psychic reactions occurred $(a)$ spontaneously, especially in partially trained animals; $(b)$ when animals began developing restlessness or nervousness and no intentional attempt was made to calm or reassure them; (c) in association with bodily stimuli, given without attempts to avoid emotional reactions; $(d)$ during a brief period of ether inhalation; $(e)$ during periods of pleasant emotion produced by the proximity to the animal of a good human or canine friend, etc.

Making allowance for the influences on the records, produced by contractions of the abdominal wall or respiratory muscles, our results have consistently shown that excitement or any other type of emotional upset leads to a prompt loss of tone and motility of the antrum, sphincter, and bulb. This inhibition ranges from slight to complete, varying with the degree and duration of the mental change. Any severe emotional upset always produced pyloric region inhibition. We obtained no indication that pylorospasm could be produced by any ordinary mental upset. During a period of transient asphyxia, however, a brief interval of hypertonicity and hypermotility preceded the predominant inhibition.

Stimulation of peripheral sensory nerves. Noxious stimuli were applied in a large number of experiments. These consisted of pulling the hair (43 experiments), tickling ( 26 experiments), pinching the skin, especially between the paws (35 experiments), pin pricks (44 experiments), stimulation, with induced current, of all readily available portions of the body (56 experiments), application of mustard oil to the skin (6 experiments), pressure on the paws, testes, or eyeballs (12 experiments each), inhalation of agreeable, disagreeable, or irritating vapors (35 experiments), smelling or licking and swallowing food (30 experiments), sudden disturbing sounds (26 experiments), and blowing air into the ear (18 experiments). In each case, the degree and duration of the irritation was varied over a wide range, from mild to moderate, and was continued until definite signs of distress were elicited. Although this type of irritation was only moderately effective, a modification of pyloric region activity was produced in practically all cases. This was invariably an inhibition of all 3 regions, which varied in degree and duration with the degree and duration of the stimulus. The irritant frequently was applied after the animal had been in the hammock for several hours, was becoming restless, and a nervous upset was easily produced. Usually, the inhibition was only moderate unless evidence of psychical disturbance developed. Complete inhibition was usually associated with a brief struggle period. Tasting, chewing, and swallowing food were among the most effective methods of temporarily inhibiting the sphincter region.

Distention of various portions of the digestive tract. In this series of experiments, a balloon connected to a mercury manometer was inserted into a portion of the gut and 15 minutes later it was inflated. Distention of the lower fourth of the esophagus (15 experiments), the second third of the duodenum (17 experiments), the jejunum, $20 \mathrm{~cm}$. distal to the sphincter (8 experiments), the lower third of the colon (20 experiments), or the rectum, including the internal and external sphincters and the anal canal (9 experiments), produced inhibition of the entire pyloric sphincter region. Some variation in results occurred between different animals or in the same animal on different trials, but in general, the results were as follows (Figure 1). The degree and duration of effect was related to the degree and duration of the distention. The inhibition developed in 5 to 60 seconds and if the distention was maintained, recovery gradually developed during the subsequent 3 to 20-minute interval. All 3 portions of the pyloric region were inhibited in a similar manner by duodenal distention, but stretching the other parts of the digestive tract was slightly less effective on the duodenal bulb than on the antrum or sphincter. The tone and motility of the sphinc- 


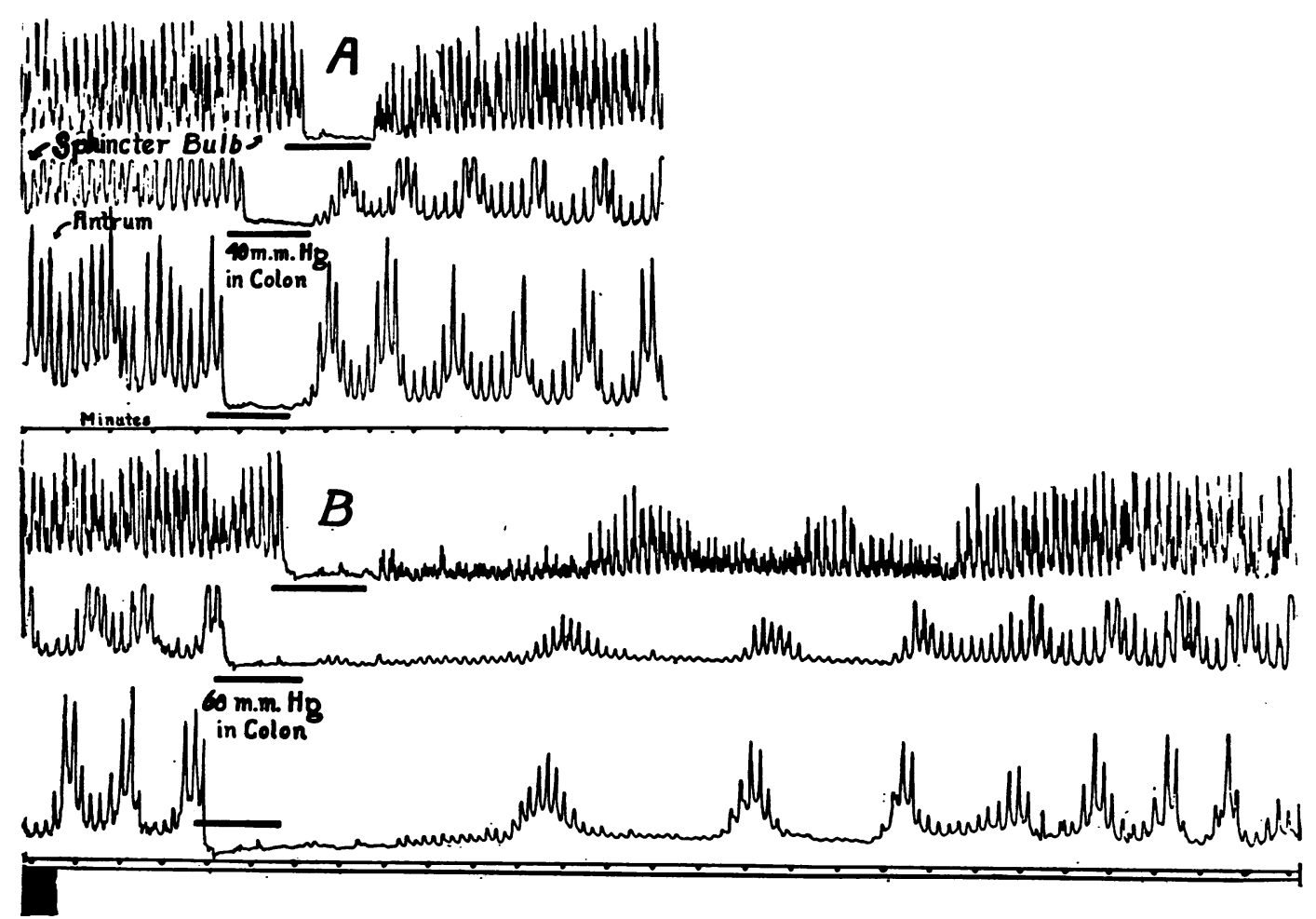

Fig. 1. Normal Dog Fasting for 18 Hours

Records from duodenal bulb, pyloric sphincter, and pyloric antrum by tandem balloon-water manometer method. The horizontal bars indicate the interval during which a balloon in the lower colon was distended; in $\mathrm{A}$, to $40 \mathrm{~mm}$. $\mathrm{Hg}$ pressure; in $\mathrm{B}$, to $60 \mathrm{~mm}$. Time intervals in minutes.

ter region usually were inhibited to a similar degree.

Of the regions studied, distention of the duodenum was most effective. Usually, a slight inhibition was obtained with pressures as low as $8 \mathrm{~mm}$. of mercury and complete inhibition with 20 to $30 \mathrm{~mm}$. The minimal effective pressures in the other parts of the gut were 10 to $15 \mathrm{~mm}$. for slight effects and 25 to $35 \mathrm{~mm}$. for marked inhibition. Complete inhibition of the entire pyloric region was repeatedly obtained from distention which produced no indication of discomfort, but with high pressures in the distending balloon, restlessness, nausea, retching, or vomiting occasionally occurred. Such reactions were obtained by stretching any of the regions of the digestive tract, but the duodenum was most sensitive in this respect. Nausea, retching, and vomiting were associated with a brief increase in tone and motility of the sphincter region (on which we will report elsewhere). It was preceded and followed by a marked inhibition of the pyloric region. During nausea, retching, and vomiting, a transient condition of pylorospasm was approached. When nausea, retching, and vomiting developed, the distention balloon usually was promptly deflated. Despite this withdrawal of the stimulus, inhibition of the sphincter region after nausea, retching, and vomiting was usually complete and persisted for 3 to 15 minutes. The ease with which nausea, retching, and vomiting could be produced provided some difficulty in successfully investigating distending balloon pressures in the higher range. Nevertheless, the effects of pressures up to 80 mm. were studied.

Mechanical irritation, produced by rubbing the duodenal mucosa with a glass rod $4 \mathrm{~cm}$. distal to the sphincter, by introducing or withdrawing balloons in any portion of the tract, or by vigorous manual pressure or massage of abdominal organs through the abdominal wall, produced an inhibition of the sphincter region persisting for 1 to 5 minutes.

Distention of the stomach (12 experiments), 
with pressures of 5 to $15 \mathrm{~mm}$., produced a slight increase in tone and motility of the sphincter region, similar to that previously reported $(25,26)$. With higher pressures, up to $45 \mathrm{~cm}$., an inhibition of the sphincter region frequently developed. Caution was required in interpreting these records, for distention of the large gastric balloon increased the intra-abdominal pressure and produced a record which could be mistaken for augmented pyloric region tonus.

Vagotomy. Distention of the duodenum, jejunum, colon, or rectum still effectively inhibited the entire sphincter region in dogs after section of the vagi above the diaphragm. In these vagotomized animals, distending pressures 10 to $20 \mathrm{~mm}$. higher than in normal subjects were required to produce comparable effects, and the latent period was 1 to 2 minutes longer. Thus, it is evident that the vagi play a role in the sphincter region inhibition, but are not essential to it. It has been reported (18) that inhibition of the body of the stomach follows intestinal distention of vagotomized dogs, but according to Thomas et al. (27), the enterogastric reflex, by which substances in the duodenum inhibit the sphincter region, does not operate after vagotomy. Hughson (14) could not produce "reflex pylorospasm" by irritation of the peritoneum after vagotomy. We observed that the application of $5 \mathrm{cc}$. portions of 0.5 per cent procaine to the duodenal mucosa, 3 times in 8 minutes, did not prevent the development of the characteristic inhibition from duodenal distention.

$X$-ray studies. Roentgenological studies ( 5 to 11) have provided most of the results interpreted as indicating that retarded gastric evacuation is frequently due to pylorospasm. Therefore, we determined ( 22 experiments), by the x-ray method, the effects of noxious bodily stimuli on gastric evacuation and on gastric and bulbar motility. We checked these observations by the simultaneous registration of the activity of the pyloric sphincter, as recorded with the pyloric diagraph (28), and by the accurate determination of the intralumen pressures in the antrum and bulb (25). Studies with the pyloric diagraph alone were also made (8 experiments) to provide rather direct information regarding sphincter activity (actually, the changes in the external (serosal) diameter of the sphincter), while the lumen of the sphincter region was free of foreign bodies. In 12 experiments, the antral and bulbar pressures were recorded while the sphincter activity was simultaneously followed by the pyloric diagraph, and this in turn was checked in 6 experiments by a miniature sphincter balloon $(4 \times 8 \mathrm{~mm}$.). In each set of experiments, half were performed in fasting animals, but for the remaining studies, the animals were fed 300 grams of corn meal mush and 92 grams of $\mathrm{BaSO}_{4}$.

In these studies, emotional states of the animal (restlessness, panting, etc.) usually produced marked retardation of gastric evacuation, a suppression of antral and bulbar tone and peristalsis, and of phasic pressure changes. The pyloric sphincter was inhibited, as was indicated by a fall in the miniature sphincter balloon record, a separation of the lead shot, and a cessation of rhythmic contractions. Similar results were obtained by feeding a small amount of food, startling the animal (an unexpected noise, flash of light, touch, slap, etc.), or the insertion of a colon balloon or rectal spreader. On the other hand, nausea and vomiting produced a temporary increase in antral, sphincter, and bulbar motility and in antral and bulbar basal and phasic pressures.

Stretching of the lower colon (30 experiments) was obtained by a balloon attached to a mercury manometer and the anal sphincter and terminal colon were stretched (14 experiments) with long sponge forceps. In each case, a range of stimulation was used, varying from the mild up to and including those producing distress (restlessness, irregular respiration, nausea, or vomiting). The effectiveness of the stimulation varied with the degree and duration of the stimulus. The invariable result was a delay in gastric evacuation. Antral and bulbar peristalsis and phasic pressure changes were suppressed and the basal pressures were lowered. The sphincter was relaxed, as was indicated by separation of the shot, cessation of rhythmic contractions, and a fall in the sphincter balloon record (Figure 2).

Pressures in the colon as low as $10 \mathrm{~mm}$. of mercury produced slight inhibition of the sphincter region, but complete inhibition required 35 to $60 \mathrm{~mm}$. pressure in fasting dogs and 50 to $80 \mathrm{~mm}$. in fed animals. It has also been observed (26) that fat in the duodenum is less effective in pro- 

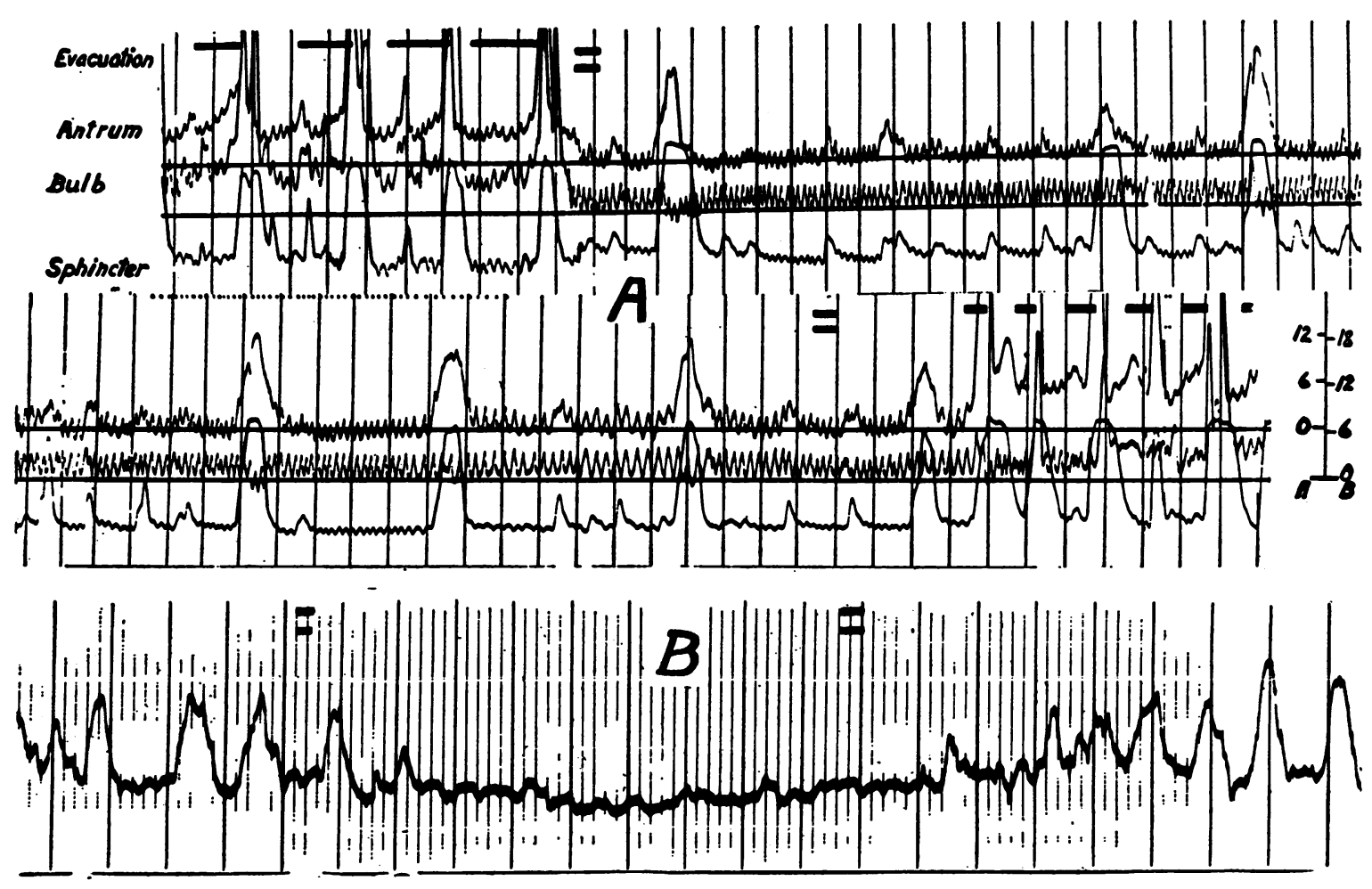

Fig. 2. Normal Dog, Fed 300 Grams Corn Meal Mush and 90 Grams BaSO4

A. Record of passage of radiopaque material through the pyloric sphincter, of antral and bulbar pressures recorded by the optical manometer, and a record of sphincter activity obtained from a miniature sphincter balloon. Scale at right-hand side, calibration of antral and bulbar pressures.

B. Record of sphincter activity obtained from the pyloric diagraph.

In each record, between the double horizontal bars, the colon was distended; in $\mathrm{A}$, to $60 \mathrm{~mm}$. $\mathrm{Hg}$; in $\mathrm{B}$ to $35 \mathrm{~mm}$. Heavy vertical lines are at 10 seconds intervals.

ducing inhibition of the sphincter region in fed than in fasting animals.

Discussion. The motor activity of the pyloric sphincter region was studied by a variety of rather direct methods. Although each of these methods taken separately has objectionable features, these objections are decidedly minimized when considered in the aggregate. We attempted to produce pylorospasm by a series of procedures, more or less similar to those which in the hands of others apparently produced such spasm. Emotional factors or stimulation of the surface of the body or the gastro-intestinal tract, in our experience, invariably failed to produce pylorospasm. In fact, loss of sphincter tone and motility was uniformly obtained. Inhibition of the pyloric antrum and duodenal bulb generally paralleled the pyloric suppression. According to our observations, the decreased antral propulsive peristalsis was responsible for the simultaneous retardation of gastric evacuation. It should be emphasized that this retarded evacuation occurred in spite of a concomitant sphincter relaxation.

Luckhardt et al. (5) reported the production of pylorospasm from mechanical trauma to the duodenal mucosa. When we repeated this experiment, and also as the result of the duodenal trauma incidentally produced during the hundreds of times we have introduced spools, balloons, or pressure recording tips into the sphincter region of our large number of experimental animals, we have obtained indications of sphincter relaxation but never of pylorospasm. The presence of food substances, hypertonic solutions, or $\mathrm{HCl}$ in the duodenum also inhibits the pyloric region and delays gastric evacuation in a manner similar to trauma of the duodenal mucosa.

So far, we have succeeded in augmenting the 
tone and motility of the pyloric sphincter region in 3 different ways. (1) The introduction into the duodenal bulb of hydrochloric acid ( 0.4 per cent) sometimes produces an increase in tone and motility of the sphincter and bulb (29). Stretching the stomach by food, fluid, or a balloon moderately increases the pyloric region tone and motility, especially if the distention involves the antrum. (3) A transient increase in motility and tone of the pyloric region develops during nausea, retching, and vomiting. Of these 3 conditions, nausea and vomiting is the only one producing a condition even remotely approaching pylorospasm. However, the reaction observed in our experiments was much too transient to be considered as pylorospasm, but it may have led other investigators to the diagnosis of pylorospasm, particularly since the types of irritation they employed would almost certainly produce nausea and vomiting.

Acceptable evidence is available that a type of experimental pylorospasm can be produced in anesthetized dogs. Thomas and Wheelon (20) and Carlson and Litt (2), employing anesthetized animals, obtained a strong pyloric contraction from electrical stimulation of the vagi or splanchnics. The latter investigators also produced pyloric closure from irritation of organs or stimulation of somatic sensory nerves. These investigators have also confirmed the observation of others that sphincter relaxation, as well as contraction, can be produced by stimulation of the vagi or splanchnics. We may speculate that the reflexes carried over these nerves exert both influences, but one effect usually predominates. Perhaps anesthesia can shift the balance and reverse the effect observed in the normal animal. It is also possible that a similar reversal may obtain in a different species or in a disease where the reflex relations are modified and a different type of stimulus is involved.

Roentgenological studies only give dependable information regarding pyloric sphincter activity when the sphincter is visualized. Thus, the usual conclusion that the non-visualizing sphincter is always closed or is in spasm is erroneous. In our experience, this is the basis for the mistaken ideas that $(a)$ the sphincter normally is closed most of the time and only opens when forced to do so by high antral or bulbar pressure, $(b)$ that substances such as fats, fatty acids, $\mathrm{HCl}$, etc., in the duodenum delay gastric evacuation by producing pylorospasm, and $(c)$ that pylorospasm is readily produced by noxious bodily stimuli. It is therefore likely that complete dependence on roentgenological evidence can lead to an erroneous diagnosis of clinical pylorospasm.

The clinical diagnosis of pylorospasm rests largely on roentgenological evidence: failure of the stomach to empty, failure of the sphincter to fill or visualize, sometimes in spite of apparently vigorous contractions of the more proximal portion of the stomach and occasionally the presence of a firm mass in the pyloric region. On the basis of this evidence, pyloro- or prepylorospasm apparently can result clinically from disturbances in the digestive tract or gall bladder, renal calculi, cardiac disease, or emotional trauma (Jordan and Lahey (30)).

From a critical standpoint, clinical pylorospasm must be distinguished from several conditions with which it frequently is grouped, e.g., thickening of the muscularis, edema, scar tissue retraction, or post-operative deformity of the sphincter region. When this is done, gastroscopic evidence, such as was presented by Gibb (31), does not confirm a high incidence of pylorospasm. This investigator observed the sphincter in 560 examinations and found it open practically all of the time and closed intermittently and for brief intervals. In 20 cases with food retention, he found the pylorus patent in every case.

Summary. The effect on the motor activity of the pyloric sphincter region of emotions, or a variety of noxious bodily stimuli applied to somatic and visceral structures, was determined on trained dogs by several rather direct methods. Under these conditions, as in several previously studied, the pyloric sphincter region (antrum, sphincter, and bulb) tended to behave as a unit; in action, the sphincter was similar, not contrary, to the antrum. Emotions and noxious stimuli did not produce pylorospasm but tended to inhibit the entire sphincter region. Emotions and noxious stimuli retarded gastric evacuation. This retardation resulted from decreased antral peristalsis. The delayed evacuation was not due to pylorospasm; in fact, it developed in spite of the pyloric 
relaxation. The claim that pylorospasm is readily produced by emotional states or noxious bodily stimuli receives little support from this experimental study or from a critical consideration of the clinical evidence.

\section{BIBLIOGRAPHY}

1. Cole, L. G., Relation of lesions of the small intestine to disorders of the stomach and cap, as observed roentgenologically. Am. J. M. Sc., 1914, 148, 92.

2. Carlson, A. J., and Litt, S., Studies on the visceral nervous system, on the reflex control of the pylorus. Arch. Int. Med., 1924, 33, 281.

3. Cannon, W. B., and Murphy, F. T., Physiologic observations on experimentally produced ileus. J. A. M. A., 1907, 49, 840.

4. Barber, W. H., and Stewart, G. D., Further observations upon reflex gastric hypermotility. Proc. Soc. Exper. Biol. and Med., 1919, 17, 155.

5. Luckhardt, A. B., Phillips, H. T., and Carlson, A. J., Contributions to the physiology of the stomach. LI. The control of the pylorus. Am. J. Physiol., 1919, 50, 57.

6. Finney, J. M. T., and Friedenwald, J., Pylorospasm in adults; its medical and surgical treatment. Am. J. M. Sc., 1921, 162, 469.

7. Aaron, C. D., Chronic appendicitis, pylorospasm and duodenal ulcer. J. A. M. A., 1915, 64, 1845.

8. Smith, F. M., and Miller, G. H., The reflex influence of the colon, appendix and gall bladder on the stomach. Arch. Int. Med., 1930, 46, 988.

9. White, F. W., Effect of stimuli from the lower bowel on the rate of emptying the stomach. Am. J. M. Sc., 1918, 156, 184.

10. Tobler, L., Uber die Eiweissverdauung im Magen. Ztschr. f. physiol. Chem., 1905, 45, 185.

11. Carnot, P., Le jeu du sphincter pylorique. Arch. d. mal. de l'apparat. digest., 1907, 1, 651.

12. Pearcy, J. F., and Van Liere, E. J., Studies on the visceral nervous system. XVII. Reflexes from the colon. 1. Reflexes to the stomach. Am. J. Physiol., 1926, 78, 64.

13. Farrell, J. I., Effect of colitis on gastric digestion. J. Lab. and Clin. Med., 1930, 15, 623.

14. Hughson, W., Reflex spasm of the pylorus and its relation to diseases of the digestive organs. Arch. Surg., 1925, 11, 136.

15. Carlson, A. J., The Control of Hunger in Health and Disease. University of Chicago Press, Chicago, 1916.

16. Ivy, A. C., The applied physiology of the gastrointestinal innervation. Am. J. Digest. Dis. and Nutrition, 1935, 1, 845.

17. Loew, E. R., and Patterson, T. L., The reflex influence of the lower portion of the large intestine on the tonus and movements of the empty stomach in dogs. Quart. J. Exper. Physiol., 1938, 28, 305.
Patterson, T. L., and Dunn, L. E., The reflex influence of the urinary bladder on the tonus and movements of the empty stomach of dogs. Am. J. Physiol., 1941, 133, P410.

Scantlebury, R. E., and Patterson, T. L., The influence of lung distention on gastric hunger motility in the bullfrog. Am. J. Physiol., 1939, 126, P619.

Brush, B. E., and Patterson, T. L., The influence of gall-bladder distention on gastric hunger motility in the dog. Am. J. Physiol., 1939, 126, P449.

18. Lalich, J., Meek, W. J., and Herrin, R. C., Reflex pathways concerned in inhibition of hunger contractions by intestinal distention. Am. J. Physiol., 1936, 115, 410.

19. Youmans, W. B., and Meek, W. J., Reflex and humoral gastro-intestinal inhibition in unanesthetized dogs during rectal stimulation. Am. J. Physiol., 1937, 120, 750.

20. Thomas, J. E., and Wheelon, H., The nervous control of the pyloric sphincter. J. Lab. and Clin. Med., 1922, 7, 375.

21. Meschan, I., and Quigley, J. P., Spontaneous motility of the pyloric sphincter and adjacent regions of the gut in the unanesthetized dog. Am. J. Physiol., 1938, 121, 350.

22. Thomas, J. E., Some physical and physiological factors involved in the regulation of gastric emptying. Rev. Gastroenterol., 1935, 2, 32.

23. Werle, J. M., et al., The mechanics of gastric evacuation. Am. J. Physiol., 1941, 131, 606.

24. Ramond, F., Le spasme du pylore. Presse Med., 1920, 28, 273.

25. Brody, D. A., Werle, J. M., Meschan, I., and Quigley, J. P., Intralumen pressures of the digestive tract, especially the pyloric region. Am. J. Physiol., 1940, 130, 791.

26. Quigley, J. P., et al., The influence of fats on the motor activity of the pyloric sphincter region and on the process of gastric evacuation studied by the balloon-water manometer and by the optical manometer-fluoroscopic technics. Am. J. Physiol., 1941, 134, 132.

27. Thomas, J. E., and Mogan, C. J., The enterogastric reflex. Proc. Soc. Exper. Biol. and Med., 1931, 28, 968.

28. Quigley, J. P., and Read, M. R., The spontaneous motility of the pyloric sphincter and its relation to gastric evacuation: The pyloric diagraph. Am. J. Physiol., 1942, 137, 234.

29. Quigley, J. P., et al., The effect of hydrochloric acid on the pyloric sphincter, the adjacent portions of the digestive tract and on the process of gastric evacuation. Am. J. Physiol., 1942, 137, 153.

30. Jordan, S. M., and Lahey, F. H., Prepyloric lesions of the stomach: medical and surgical aspects. Gastroenterology, 1943, 1, 1.

31. Gibb, W. T., A theory concerning the manner in which the stomach empties itself. Ann. Int. Med., 1942, 16, 94. 